\title{
Effects of Long-Term Exposure to Traffic-Related Air Pollution on Lung Function in Children
}

\author{
Erica S. Schultz ${ }^{1}$ • Augusto A. Litonjua ${ }^{2}$ • Erik Melén ${ }^{1,3,4}$
}

Published online: 27 May 2017

(C) The Author(s) 2017. This article is an open access publication

\begin{abstract}
Lung function in early life has been shown to be an important predictor for peak lung function in adults and later decline. Reduced lung function per se is associated with increased morbidity and mortality. With this review, we aim to summarize the current epidemiological evidence on the effect of traffic-related air pollution on lung function in children and adolescents. We focus in particular on time windows of exposure, small airway involvement, and vulnerable sub-groups in the population. Findings from studies published to date support the notion that exposure over the entire childhood age range seems to be of importance for lung function development. We could not find any conclusive data to support evidence of sup-group effects considering gender, sensitization status, and asthma status, although a possibly stronger effect may be present for children with asthma. The long-term effects into adulthood of exposure to air pollution during childhood remains unknown, but current studies suggest that these deficits may be propagated into later life. In addition, further research on the effect of exposure on small airway function is warranted.
\end{abstract}

This article is part of the Topical Collection on Allergies and the Environment

Erica S. Schultz

erica.schultz@ki.se

1 Institute of Environmental Medicine, Karolinska Institute, Box 210, SE-171 77 Stockholm, Sweden

2 Channing Division of Network Medicine, Department of Medicine, Brigham and Women's Hospital and Harvard Medical School, 181 Longwood Ave, Boston, MA, USA

3 Sachs' Children's Hospital, Södersjukhuset, Stockholm, Sweden

4 Centre for Occupational and Environmental Medicine, Stockholm County Council, Stockholm, Sweden
Keywords Adolescence · Asthma · Cohort · Epidemiology · Sensitization $\cdot$ Small airways $\cdot$ Spirometry

\section{Introduction}

Air pollution (outdoor and indoor) is a global problem and one of the most important environmental determinants for human health. About 300 million children worldwide breathe highly toxic air, defined as levels six or more times exceeding international guidelines [1]. Indoor and outdoor air pollution is linked to 1 in 10 deaths in children under 5 years of age, and out of these, about $20 \%$ are attributable to outdoor air pollution levels [2]. The most important process contributing to levels of ambient air pollution in urban settings relates to the combustion of fuels. Due to the proximity between people and sources, road traffic is particularly important for the population exposure to ambient air pollution in developed countries.

Lung development starts in utero, and exposure to air pollution prenatally has been shown to negatively affect respiratory health [3]. Considerable maturation of the lungs continues after birth, which makes the lungs potentially vulnerable to the effects from exposure to air pollution also postnatally. Infants are relatively immobile and are often in a pram during outdoor transportation, at the level of motor exhaust emissions. Infants and children may also be more exposed to air pollution compared to adults relative to their size, due to higher ventilation per minute. In addition, the immune system of infants and young children is not fully developed, which may contribute to an increased vulnerability to the effects of exposure to air pollution [4].

Lung function in early life has been shown to be an important predictor for peak lung function in adults and later decline $[5,6]$. Reduced lung function per se is associated with increased morbidity and mortality, even among healthy non- 
smoking individuals with only modestly reduced lung function $[7,8]$. Longitudinal studies have revealed that, taking height and gender into consideration, the deviation of an individual's value of lung function from the population average remains rather constant independent of age. This is known as tracking of lung function, and a person is said to follow his or her own trajectory if crude lung function values are increasing as expected, relative to age, height, and gender [5, 9]. From a public health perspective, it is therefore of great interest to evaluate the effect of modifiable environmental factors such as pre- and postnatal air pollution exposure on children's lung function, given the potential long-term effects.

With this review, we aim to summarize the current epidemiological evidence on the effect of traffic-related air pollution on lung function in children and adolescents. We will particularly focus on time windows of exposure, small airway involvement, and vulnerable sub-groups in the population.

Search strategy and selection criteria

We searched the PubMed databases for publications from Jan 2006 to March 2017, with the search terms (TRAP OR (traffic AND(pollut* OR emission* OR PM OR NO OR particle*))) AND ("Lung function" OR spirometry OR "pulmonary function" OR "forced expiratory" OR "FEV*" OR "Impulse oscillometry" OR "forced oscillat* techniq*" OR "FOT" OR "lung volume" OR "small airway*" OR "peripheral airway") AND (Children* OR "school-age*" OR "pre-school*" OR infant* OR adolesce*), as well as (TRAP OR traffic OR pollut* OR emission* OR PM OR NO OR particle*))) AND ("Impulse oscillometry" OR "small airway*" OR "peripheral airway*").

From PubMed search, 258 articles were identified. We also identified references from the bibliographies of these publications and from a review article by Gotschi et al. from 2008 [10].

Included articles had longitudinal air pollution data (about 1-year estimates) or proxies for long-term traffic-related air pollution (like traffic counts/density). In summary, 32 articles with cross-sectional lung function data (Table 1) were included, as were 12 articles with longitudinal lung function data (Table 2).

\section{Air Pollution Exposure}

Ambient (outdoor) air pollution constitutes a complex mixture of compounds, which vary in concentration depending on sources, geography, topography, wind direction and speed, temperature, ultraviolet radiation, and relative humidity. The concentrations of pollutants may be correlated both in time and space, because they come from the same sources and are distributed similarly. Therefore, in studies of health effects, it may be difficult to discern the importance of one pollutant from the other.

Ambient air pollution consists of organic and inorganic liquid and solid particles suspended in air (particulate matter-PM), as well as different type of gases such as ozone $\left(\mathrm{O}_{3}\right)$, nitrogen oxides $\left(\mathrm{NO}_{\mathrm{x}}\right)$, and carbon monoxide $(\mathrm{CO})$, as well as vapors, as volatile organic carbons (VOCs) [55].
Classification of particles is often according to size, and this provides information about possible health effects. For example, particulate matter with an aerodynamic diameter of less than $10 \mu \mathrm{m}\left(\mathrm{PM}_{10}\right)$ is inhalable and reaches the lower airways and is subdivided into $\mathrm{PM}_{\text {coarse }}$ (PM with a diameter between 2.5 and $10 \mu \mathrm{m}$ ), which reach the proximal airways, and $\mathrm{PM}_{2.5}(\mathrm{PM}<2.5 \mu \mathrm{m})$, which reach the more peripheral regions of the lungs where gas exchange occurs. Ultrafine particles consist of those with a diameter of less than $0.1 \mu \mathrm{m}$, which contribute little to the total mass but are higher in numbers, have a large surface area, and are suggested to reach past the alveolar wall into the blood circulation [56].

\section{Proposed Mechanisms Related to Health Effects}

The exact mechanisms by which air pollution affects the lungs and airways are not known. It has been hypothesized that oxidative stress and airway inflammation are important processes [57]. It has for example been suggested that inhaled particles provoke the generation of reactive oxygen species. This, as well as direct damage by highly oxidative gases such as ozone and $\mathrm{NO}_{2}$, induces oxidative stress and inflammatory responses [55]. Epigenetics has been proposed as one of the links between exposure to air pollution and respiratory health effects, for example through methylation of genes involved in immune-mediated inflammatory response $[58,59]$. In studies of human histological lung tissue, correlations have been observed between exposure to high PM levels and small airway remodeling by greater amounts of fibrous tissue and smooth muscle cells [60].

Studies investigating exhaled nitric oxide in humans support the notion that inflammatory processes may play a role for the observed respiratory health effects by exposure to air pollution [61]. Nitric oxide is an established biomarker of airway inflammation, and several studies show a relation between exposure to air pollution and increased levels of the exhaled fraction of nitric oxide (FeNO). This has been observed for short-term exposures, long-term exposures, markers of traffic-related air pollution, and even in children with no history of airway damage [61].

\section{Air Pollution Exposure and Lung Function in Children and Adolescents}

A number of epidemiological studies have investigated the association between long-term exposure to traffic air pollution and lung function in children and adolescents, and evidence on the negative effects of exposure to air pollution on respiratory health is accumulating. The studies with individual exposure assessment and in case of aggregated data use, studies with at least three communities included are summarized in Tables 1 (cross-sectional studies) and 2 (longitudinal studies). 


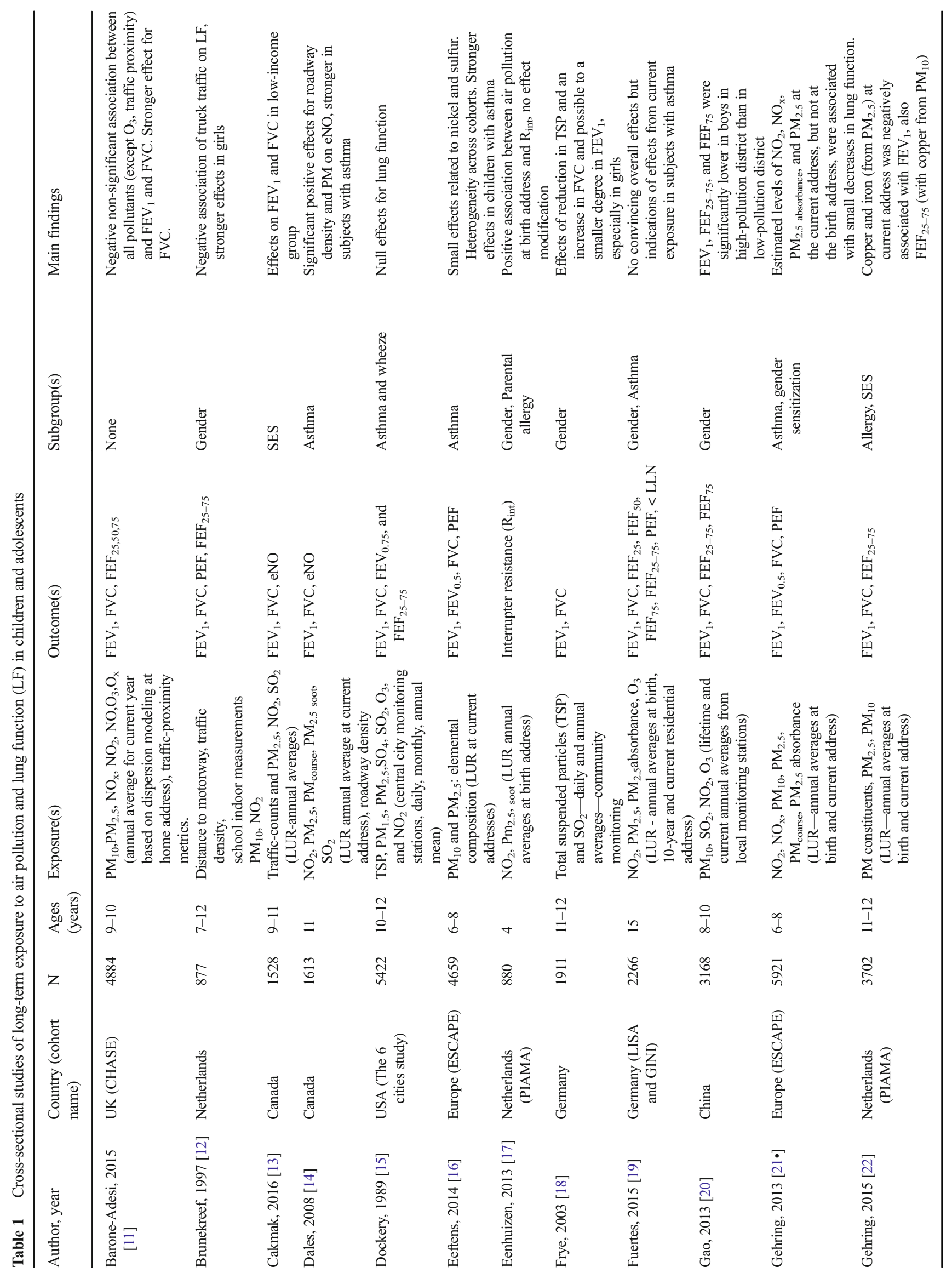




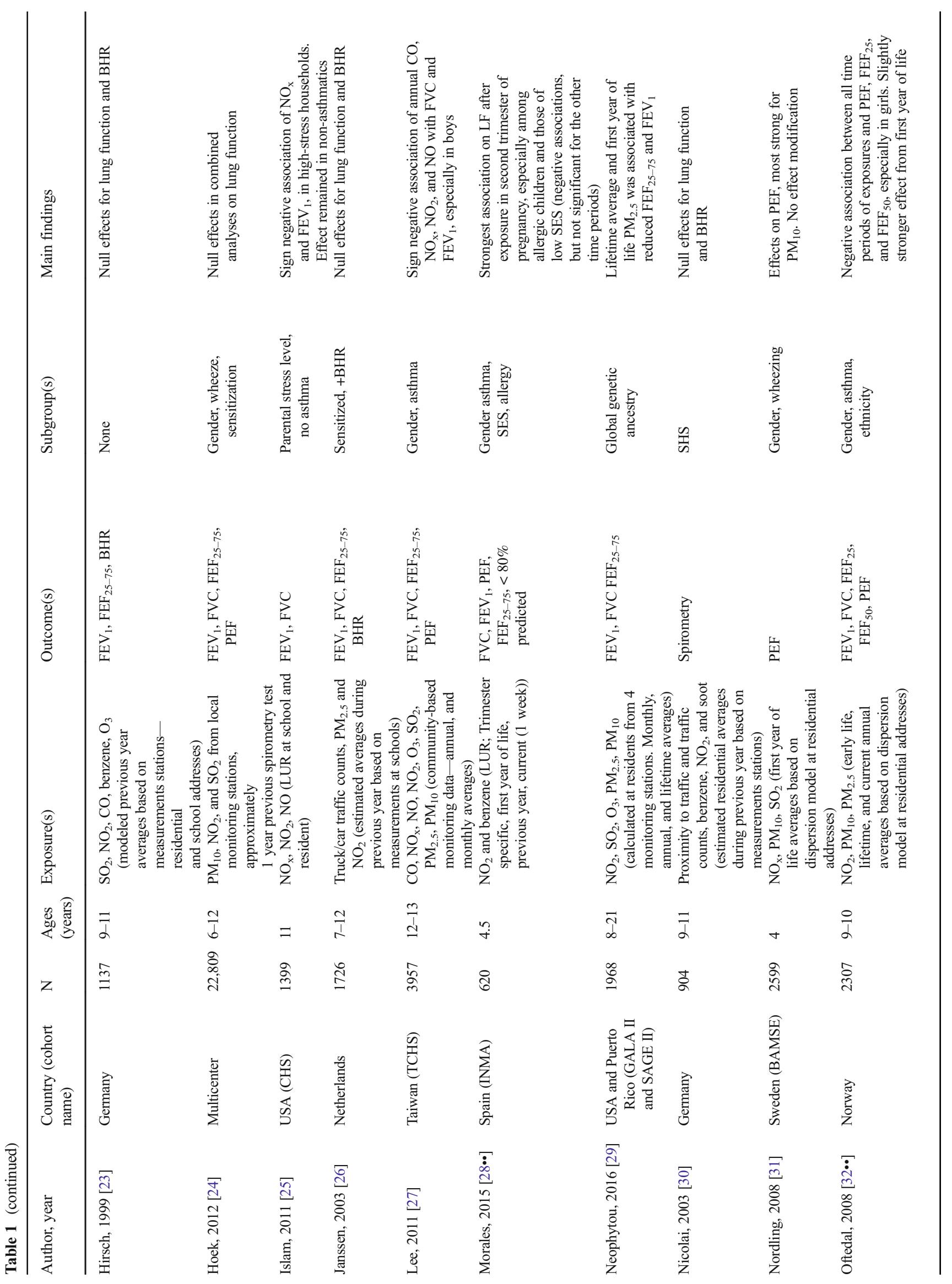




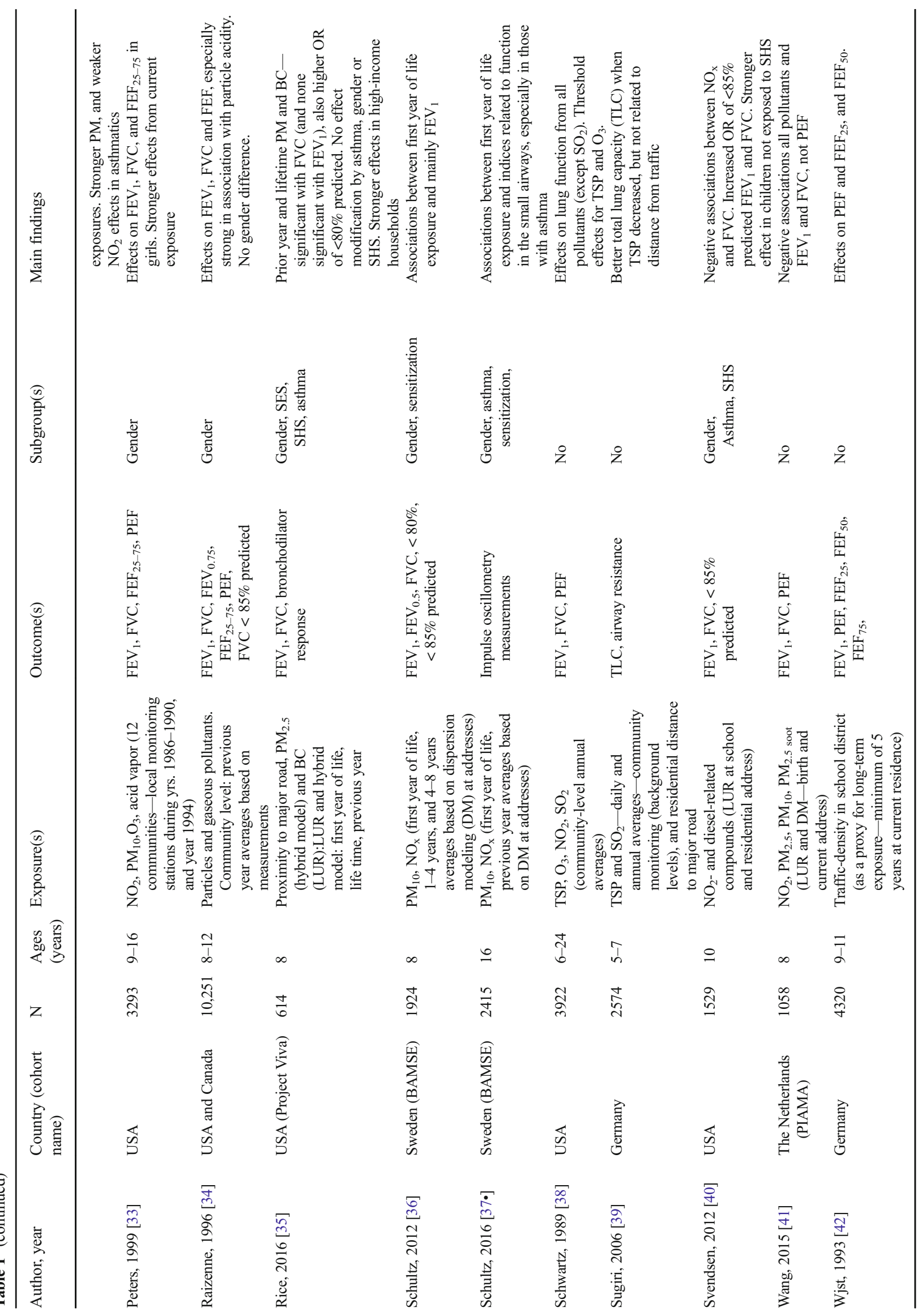




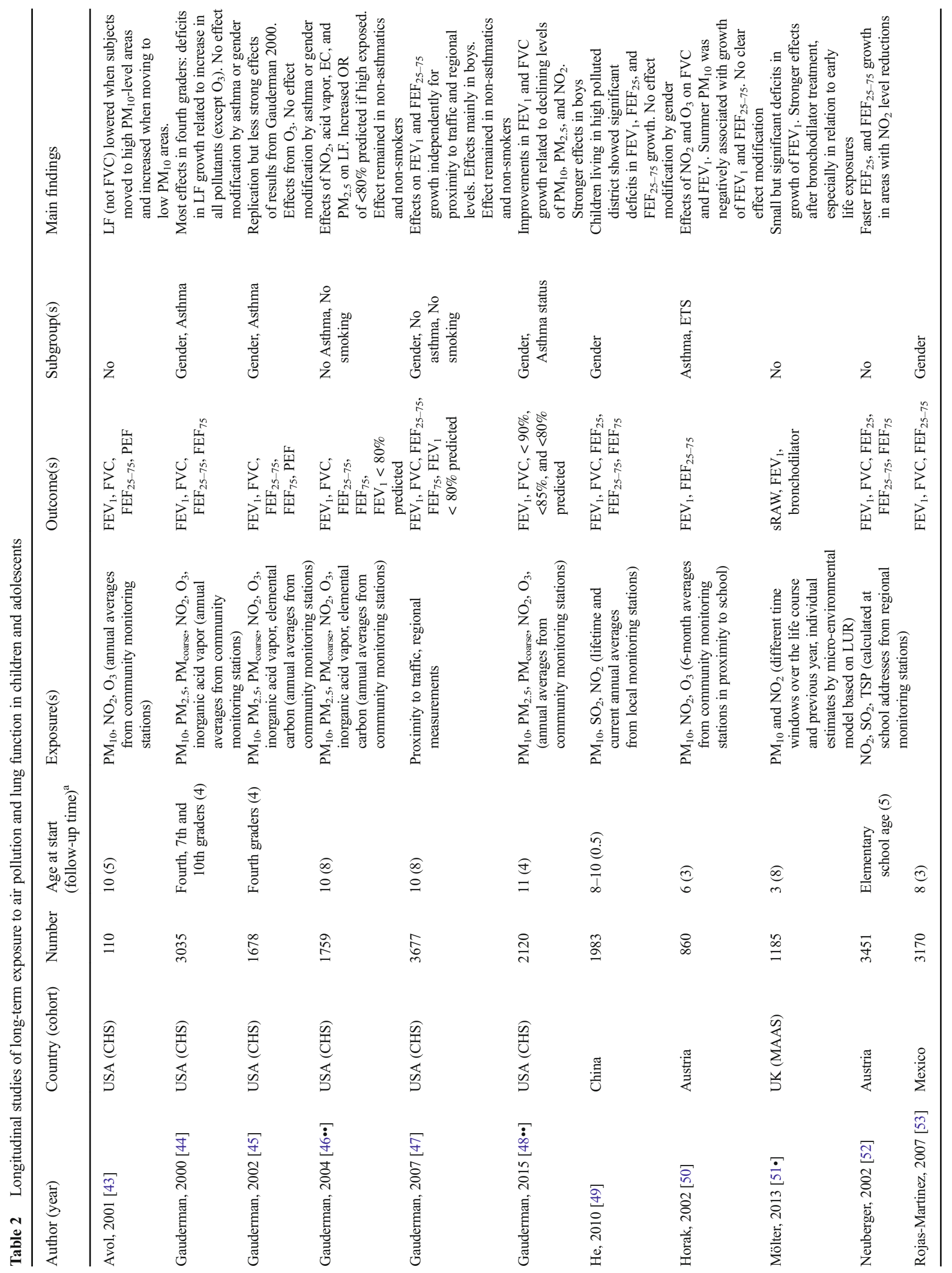


Most studies report of lung function data from a single point in time (see Table 1; 32 cross-sectional studies vs. 12 with longitudinal data). The most commonly reported index is forced expiratory volume in $1 \mathrm{~s}\left(\mathrm{FEV}_{1}\right)$, representing mainly the mechanical properties of the large and medium-sized airways, followed by the forced vital capacity (FVC), reflecting lung size. Linear statistical models are generally used. Studies have compared lung function levels in children living in different communities with varying levels of ambient air pollution measured at central monitoring stations or at schools [15, $18,27,30,33,34,38,39,43-45,46 \bullet \bullet, 49,50,52,53]$. Traffic measurements such as traffic density or proximity to highways have also been used as exposure estimates [12, 14, 26, 30, 39, 42], as well as modeling individual data using land use regression (LUR) models [13, 14, 16, 17, 19, 22, 25, 28••, 35] or dispersion models (DMs) $[31,32 \bullet \bullet, 36,37 \bullet, 41,54 \bullet \cdot]$. Most but not all studies $[15,23,26,30]$ have observed negative impact from traffic-related air pollution on lung function.

A general finding seems to be a larger effect estimate observed for $\mathrm{FEV}_{1}$ than for FVC. This pattern has been observed in studies from Austria [52], China [20], the USA [25, 44, 45, 47, 48••], Puerto Rico [29], Sweden [36, 54••], and Norway $[32 \cdot \bullet]$, even though many of these studies observed the strongest effect estimate for mid-expiratory flows $\left(\mathrm{FEF}_{25-75}\right)$. However, FVC has in some studies shown stronger associations than $\mathrm{FEV}_{1}[33,35,40,41,53]$.

The effect estimates across studies, i.e., change in mean values of lung function, are not always straightforward to compare and interpret, as the exposure usually differ between studies. For example, the mixture of components may differ between the studies due to differences in car fleet, road wear, use of studded tires, and fuel composition. Most epidemiological studies using modeled exposures cannot separate the different components of the emissions effectively [16, 22]. Because of the diversity across studies, we desist from reporting quantitative summary of effects. However, when reduction in lung function is reported in association with traffic-air pollution exposure, it is ususally with deficits of a few percent $(0.5-3 \%)[10,11,21 \bullet]$.

An average reduction in lung function of a few percent has from an individual perspective likely only minor physiological effects. A small shift in the population distribution of lung function may, however, increase the prevalence of subjects presenting lung function values below clinical thresholds, as seen in studies that show increased risk of having less than 80 or $85 \%$ of the predicted $\mathrm{FEV}_{1}$ and/or FVC values [28••, 34-36, $40]$, or less than the lower limit of normal $(<-1.645 \mathrm{SD})$ [54••]. A substantial improvement in public health may subsequently follow decreased air pollution levels, and this effect was recently seen in a publication from the Children's Health Study in California. In this study, Gauderman and colleagues initiated and followed three cohorts during separate calendar periods, at the same time as air pollution levels improved [48••]. 
The authors observed that the risk of exhibiting $\mathrm{FEV}_{1}$ values below $80 \%$ of predicted at 15 years of age declined from 7.9 to 6.3 to $3.6 \%$ across the three time periods, indicating a substantial improvement in public health following decreased levels of air pollution.

\section{Timing of Air Pollution Exposure}

Although several studies highlight the importance of exposures prenatally or during infancy for subsequent respiratory health $[9,62,63]$, until recently, only a few studies had investigated exposure during the infancy period in relation to lung function in children $[31,32 \bullet \cdot$ and none in adolescents. The majority of published cross-sectional and longitudinal studies have only investigated later life exposures (usually around school ages, see Tables 1 and 2), and the potential dynamic changes of exposure to air pollution during the life-course and subsequent influences on lung function growth remain largely unknown.

To date, there are eight studies that have reported on the relative impact of early life vs. current exposure to trafficrelated air pollution. A Norwegian cohort study of 2307 9and 10-year-olds showed that both early life and lifetime exposure to $\mathrm{PM}_{10}$ and $\mathrm{NO}_{2}$ were negatively associated with lung function $[32 \bullet \cdot]$, even though early life exposure had slightly stronger effects. A meta-analysis of five European birth cohorts within the ESCAPE collaboration showed associations mainly with exposures at the current address and lung function at 6-8 years of age, while no significant association was seen with exposures at the address at birth [21•]. Mölter and colleagues have followed 1185 children from birth to 11 years of age within the MAAS cohort [51 $\bullet$ and observed strong effects mainly from exposure to $\mathrm{PM}_{10}$ during early life and postbronchodilator $\mathrm{FEV}_{1}$ at 5 and 11 years of age. Fuertes et al. report from a German cohort of 226615 -year-olds overall null findings irrespective of exposure time periods [19]. In a recent report, Rice and co-authors investigated 614 children (mean age 7.7 years) and concluded that the first year of life, lifetime, and past year exposure to $\mathrm{PM}_{2.5}$ and black carbon were all negatively associated with mainly FVC (not as strongly with $\mathrm{FEV}_{1}$ ), but that only the latter two time periods were statistically significant [35]. Studies from the Swedish birth cohort BAMSE report associations mainly from first year of life exposure to $\mathrm{PM}_{10}$ and/or $\mathrm{NO}_{\mathrm{x}}$ with $\mathrm{FEV}_{1}$ at 8 years of age [36], at 16 years of age [54••], and with impulse oscillometry measurements at 16 years of age [37॰].

In summary, the evidence of a particular important air pollution exposure time window for subsequent lung function appears inconclusive, and findings from studies published to date rather support that exposure over the entire age range is of importance. Most longitudinal studies are supporting this observation, with attenuated lung function growth in relation to air pollution exposure during later childhood and adolescence
$[46 \bullet \bullet, 51 \bullet, 53]$ being reported, as well as recovery of previous deleterious effects in subjects moving to less polluted areas [43]. In one study (from the BAMSE cohort), no association was observed for the change of lung function between childhood and adolescence, for any of the explored life-time exposure time windows [54••]. The authors highlight the fact that the levels of air pollution decreased during the course of the study, limiting the possibility of discerning the importance of exposure during adolescence. Most studies on lung function growth focus only on exposure during later life [ $43-45,46 \bullet$, $49,50,53]$, and the potential impact of exposures during the first year of life in these cohorts is therefore unknown.

\section{Small Airways}

The small airways are by convention defined as those with an airway diameter of $2 \mathrm{~mm}$ or less (in adults). This corresponds to approximately airway generation 8 and more distally and comprises the more peripheral conducting airways (up to generation 15), as well as the bronchioles and alveolar regions where gas exchange occurs. For many lung diseases, like chronic obstructive pulmonary disease (COPD) and asthma, the small airways are a major site of pathology $[64,65 \cdot$, and the severity of disease is often rather significant before changes in spirometry measurements appear [66]. As the small airways are relatively difficult to study, they are sometimes referred to as "the quiet zone" of the lung [67].

Most investigations linking air pollution exposure to lung function have employed measurements of total airway resistance and large rather than small airway function measured using spirometry [68]. In experimental studies on mice, small aerosol particles of a size range typical of traffic-related air pollution are deposited in the small airways [69].

There are reports of associations between exposures to air pollution and forced mid-expiratory flows, like $\mathrm{FEF}_{25-75}$, suggesting that the results represent small airway effects $[22,44$, $49,50,52]$. Although flows measured in the middle or at the end of a forced expiration generally offer insight of the more peripheral airway, the interpretation has lately been subject to debate [70]. Abnormalities in these flow indices are not specific to small airway disease [71], and it has been suggested that the mid-expiratory flows do not contribute additional information over what is provided by $\mathrm{FEV}_{1}$ and $\mathrm{FVC}$ [68].

An alternative measure of the small airways that may be feasible in an epidemiological setting is assessment of the residual volume (RV) using plethysmography. This index provides sensitive measure of gas trapping and hyperinflation, although not specific to small airway involvement [67]. Inert gas washout and forced oscillation techniques, such as impulse oscillometry (IOS), are methods that may discriminate between large and small airway effects $[67,72,73]$. In recent years, these techniques have become commercially available and easily accessible. 
Despite advances with peripheral airway assessment, it is rarely investigated whether exposure to traffic-related air pollution influences small airway function. In a panel study of 163 children aged 7-10 years in Austria, IOS indices related to peripheral airway resistance was increased in relation to shortterm exposure to air pollution [74]. Following 174 adults exposed to dust/fume from the World Trade Center collapse with airway symptoms and normal spirometry revealed abnormalities in the peripheral airways assessed with IOS in $68 \%$ of the subjects [75]. In the same group of individuals, RV/total lung capacity was elevated in approximately $33 \%$ of subjects, also indicative of small airway involvement. In 2415 children from the Swedish BAMSE cohort, $\mathrm{NO}_{\mathrm{x}}$-exposure from the first year of life was associated with increased resistance in indices related to peripheral airway function also assessed with IOS at 16 years of age $[37 \bullet]$.

To summarize, few studies have addressed small airway disease in relation to air pollution exposure to date, although associations between exposure and small airway involvement have been reported. Given the importance of small airway function in asthma and COPD, further studies are warranted.

\section{Susceptible Subgroups}

In our modern society, everybody is more or less exposed to air pollution. However, certain people or subgroups in the population may be more susceptible to negative outcomes following exposure. For the studies included in the present review, we have focused on sub-analyses with respect to asthma, sensitization, and gender status.

\section{Gender Differences}

Gender differences on lung function in response to air pollution or other environmental stimuli may be present due to inherited differences in lung and airway development. For example, surfactant production starts earlier in the lungs of neonatal females than males [76], which may be one reason why infant females have lower airway resistance and higher air-flow rates compared to infant males [77]. In addition, males present already at birth with a higher total number of alveoli and alveolar surface area than females do, but at the same time, the growth of the airways lags behind, resulting in relatively more narrow airways in infant to adolescent males compared with females (known as dysanaptic growth) [76]. Males may, therefore, during infancy, childhood, and early adolescence have a pulmonary phenotype more susceptible to the deleterious effects of air pollution exposure [78]. During puberty, however, the risk in males compared with females may become reversed as several studies indicate influence by estrogens (female sex hormone) on increased incidence and severity of asthma [79]. Thus, a gender-related vulnerability to the detrimental effects from exposure to air pollution may be influenced by age.

Several of the published epidemiological studies within the area of this review have presented stratified analyses based on gender, but results have not been consistent. Six studies show stronger effect of air pollution exposure in males compared

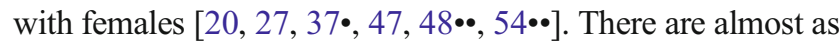
many reporting stronger effects in girls $[12,18,32 \bullet \bullet, 33]$ and a majority showing no differences in associations [17, 34, 40, $44,45,49,53]$. In addition, the mixed results regarding the role that gender has in relation to air pollution-lung function association is not obviously explained by age, as the observed differences in results cover the entire age range. Based on the published studies to date, there seems to be no conclusive evidence regarding gender-pollution interaction effects on lung function.

\section{Asthma}

Data regarding asthma as an effect modifier for the association between traffic air pollution and lung function are accumulating, although still limited. The majority of reports from the Children Health Study in the USA show no effect modification by asthma $[25,44,45,46 \bullet \bullet, 47,48 \bullet \bullet$. Additional studies also show no differences in relation to asthma status: Svendsen and colleagues including 1529 10-year-olds in El Paso, Texas [40]; Schultz and colleagues from the 16-year BAMSE cohort [54••]; and Rice and colleagues in 614 children aged 8 years [35]. Stronger effects in those with asthma are, however, suggested from several studies [14, 19, 32••, 37•]. For example, Eeftens report from the ESCAPE collaboration small effects from nickel and sulfur (part of the air pollution mixture) on lung function especially in children with asthma [16]. Dales et al. observed stronger associations between roadway density and particles on the exhaled nitrogen oxide in children with asthma, indicative of increased airway inflammation [14]. Stronger association for children with asthma was also seen in the BAMSE cohort for small airway indices assessed with $\mathrm{IOS}$ [37•] (but not for $\mathrm{FEV}_{1}$ [54••]).

There is a risk that many studies are underpowered to detect significant effect modification by asthma status, which may explain some of the null findings. Weaker effects in children with asthma is, to our knowledge, seldom reported [32••], which may support the conclusion that if effect modification by asthma exists, it points towards an increased effect in children with asthma.

\section{Sensitization}

Effect modification of air pollution-lung function associations by sensitization has not been well investigated in epidemiological studies. In one study, Morales and colleagues found stronger associations on $\mathrm{FEV}_{1}$ in allergic (allergic asthma, 
atopic dermatitis, eczema, or allergic rhinitis) 4.5-year-olds exposed to air pollutants during pregnancy and lifetime, compared with non-allergic children [28••]. Janssen and colleagues reported that associations between truck-traffic counts and respiratory symptoms were only observed among children with bronchial hyper-responsiveness and/or sensitization [26], indicating a sensitive subgroup. However, no associations were observed in the same study regarding spirometry outcomes. In studies from Schultz et al. from the BAMSE cohort, the results from subgroup analyses differed depending on whether the outcome was assessed at 8 or 16 years of age. A stronger association between the first year of life exposure to $\mathrm{PM}_{10}$ and $\mathrm{FEV}_{1}$ at 8 years of age was suggested in those sensitized than not sensitized. However, the effect modification was not statistically significant [36]. At 16 years of age, no association difference between sensitized vs non-sensitized subjects was seen $[54 \cdot \bullet]$. As part of the ESCAPE project, stratified analyses based on sensitization status for the relation between air pollution exposure and lung function at $6-8$ years of age did not reveal evidence of any effect modification [21•].

Evidence supporting sensitization as an effect modifier comes from a high-risk cohort study, where the authors observed that early exposure to allergens in combination with secondhand smoke exposure increased the risk for incident asthma, compared with having neither of the exposures [80]. Such findings are supported by controlled exposure studies $[81,82 \cdot]$.

The mechanisms behind a potential effect modification are not clear, but it has been suggested that genetically susceptible children more often present with impaired epithelial barrier function, which subsequently increases the airway's vulnerability to early life air pollution exposure [83]. Epigenetic effects on DNA have been proposed as a potential link by which sensitization-pollution interaction influences the lung function [84]. Based on the identified epidemiological studies included in this review, evidence for effect modification by sensitization status of the relation between air pollution exposure and lung function remains inconclusive.

\section{Conclusions and Future Directions}

As much as $85 \%$ of the world's population live in cities with outdoor air pollution levels exceeding the WHO Air Quality Guidelines for $\mathrm{PM}_{10}$ [2]. The trend towards global urbanization implies that more and more people will become highly exposed if further control of emissions is not applied. We conclude that early life and school-age exposure to air pollution has a negative impact on lung function, at least up to adolescence (Fig. 1). Whether these lung function deficits persist into adulthood, and subsequently result in a reduced maximally attained lung function, or a shortened growth phase, remains unknown. However, based on prior studies of lung function changes over time, these studies suggest that these affected children will continue to have lower lung function than those who were exposed to lower levels of pollutants, especially if they continue to be exposed. There is therefore a need to follow pregnancy and birth cohorts with air pollution data up to adulthood when the plateau of lung function is reached. The relative impact of pregnancy vs. early life
Fig. 1 A schematic illustration of effects on lung function from long-term traffic-related air pollution (TRAP) exposure. The $Y$-axis corresponds to lung function and the $X$-axis corresponds to time (age). The blue line illustrates normal lung function growth and decline, with a maximum in young adulthood. The dark red line illustrates lung function growth slightly less than normal due to exposure of trafficair pollution. The long-term effect of air pollution exposure during childhood remains largely unknown

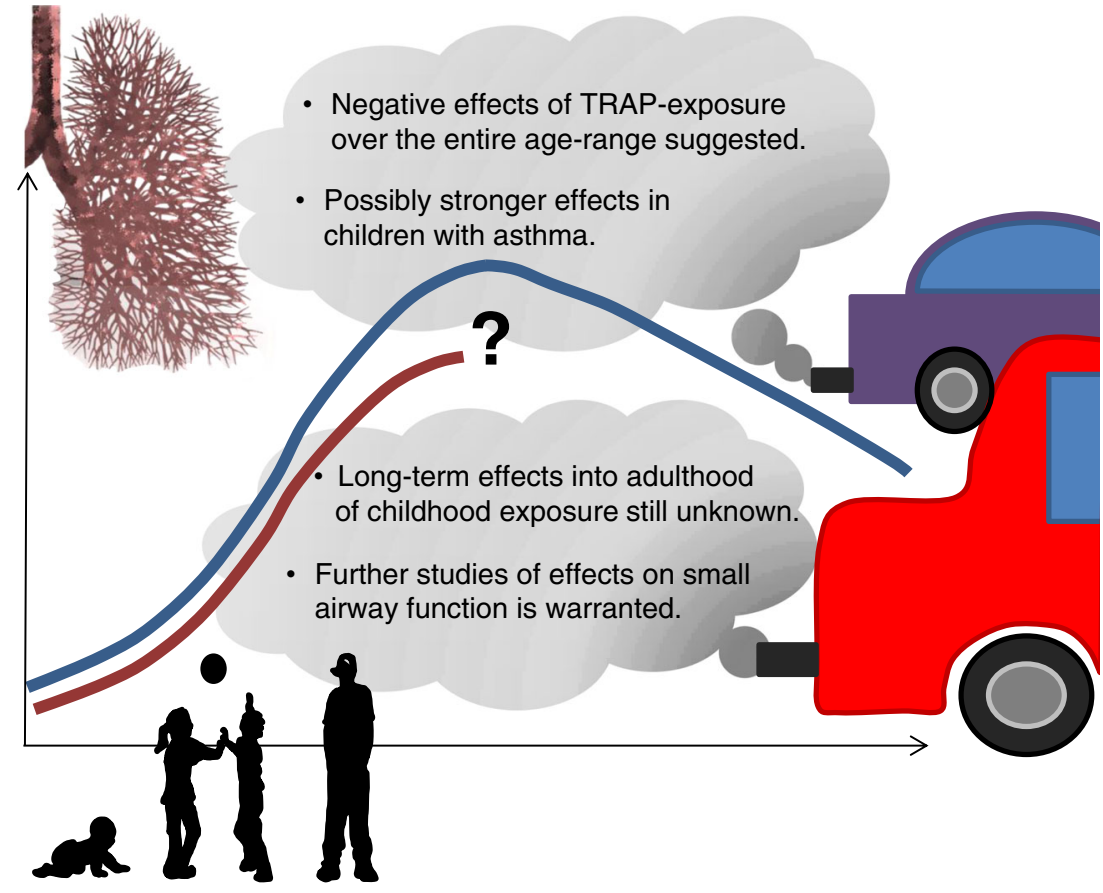


exposure is sparsely investigated and when initiating new cohorts, efforts should be made to capture both pregnancy and lifetime exposures and measure lung function already in infancy. Findings from studies published to date support that exposure over the entire childhood age range seems to be of importance for lung function development. In this review, we have also evaluated potential effect modification by gender, asthma status, and sensitization but could not find any conclusive data to support evidence of specific sup-group effects. Most studies have used spirometry indices to evaluate lung function in relation to air pollution exposure. A handful of recent studies have used other methods such as impulse oscillometry techniques to also assess small airway involvement, and further research in this area is warranted.

\section{Compliance with Ethical Standards}

Conflict of Interest The authors declare no conflicts of interest relevant to this manuscript.

Human and Animal Rights and Informed Consent This article does not contain any studies with human or animal subjects performed by any of the authors.

Open Access This article is distributed under the terms of the Creative Commons Attribution 4.0 International License (http:// creativecommons.org/licenses/by/4.0/), which permits unrestricted use, distribution, and reproduction in any medium, provided you give appropriate credit to the original author(s) and the source, provide a link to the Creative Commons license, and indicate if changes were made.

\section{References}

Papers of particular interest, published recently, have been highlighted as:

- Of importance

•• Of major importance

1. UNICEF Clear the air for children: the impact of air pollution on children. Edited by. NewYork: UNICEF; 96. [UNICEF (Series Editor); 2016.

2. World Health Organization. Ambient air pollution: a global assessment of exposure and burden of disease. WHO report. 2016. Retreived from http://apps.who.int/iris/bitstream/10665/250141/1/ 9789241511353-eng.pdf.

3. Korten I, Ramsey K, Latzin P. Air pollution during pregnancy and lung development in the child. Paediatr Respir Rev. 2017;21:38-46.

4. Holt PG, Jones CA. The development of the immune system during pregnancy and early life. Allergy. 2000;55:688-97.

5. Stern DA, Morgan WJ, Wright AL, Guerra S, Martinez FD. Poor airway function in early infancy and lung function by age 22 years: a non-selective longitudinal cohort study. Lancet. 2007;370:758-64.

6. Lange P, Celli B, Agusti A, Boje Jensen G, Divo M, Faner R, Guerra S, Marott JL, Martinez FD, Martinez-Camblor P, et al. Lung-function trajectories leading to chronic obstructive pulmonary disease. N Engl J Med. 2015;373:111-22.

7. Schunemann HJ, Dorn J, Grant BJ, Winkelstein W Jr, Trevisan M. Pulmonary function is a long-term predictor of mortality in the general population: 29-year follow-up of the Buffalo Health study. Chest. 2000;118:656-64.

8. Young RP, Hopkins R, Eaton TE. Forced expiratory volume in one second: not just a lung function test but a marker of premature death from all causes. Eur Respir J. 2007;30:616-22.

9. Stocks J, Hislop A, Sonnappa S. Early lung development: lifelong effect on respiratory health and disease. Lancet Respir Med. 2013;1:728-42.

10. Gotschi T, Heinrich J, Sunyer J, Kunzli N. Long-term effects of ambient air pollution on lung function: a review. Epidemiology. 2008;19:690-701.

11. Barone-Adesi F, Dent JE, Dajnak D, Beevers S, Anderson HR, Kelly FJ, Cook DG, Whincup PH. Long-term exposure to primary traffic pollutants and lung function in children: cross-sectional study and meta-analysis. PLoS One. 2015;10:e0142565.

12. Brunekreef B, Janssen NA, de Hartog J, Harssema H, Knape M, van Vliet P. Air pollution from truck traffic and lung function in children living near motorways. Epidemiology. 1997;8:298-303.

13. Cakmak S, Hebbern C, Cakmak JD, Vanos J. The modifying effect of socioeconomic status on the relationship between traffic, air pollution and respiratory health in elementary schoolchildren. J Environ Manag. 2016;177:1-8.

14. Dales R, Wheeler A, Mahmud M, Frescura AM, Smith-Doiron M, Nethery E, Liu L. The influence of living near roadways on spirometry and exhaled nitric oxide in elementary schoolchildren. Environ Health Perspect. 2008;116:1423-7.

15. Dockery DW, Speizer FE, Stram DO, Ware JH, Spengler JD, Ferris BG Jr. Effects of inhalable particles on respiratory health of children. Am Rev Respir Dis. 1989;139:587-94.

16. Eeftens M, Hoek G, Gruzieva O, Molter A, Agius R, Beelen R, Brunekreef B, Custovic A, Cyrys J, Fuertes E, et al. Elemental composition of particulate matter and the association with lung function. Epidemiology. 2014;25:648-57.

17. Eenhuizen E, Gehring U, Wijga AH, Smit HA, Fischer PH, Brauer M, Koppelman GH, Kerkhof M, de Jongste JC, Brunekreef B, et al. Traffic-related air pollution is related to interrupter resistance in 4year-old children. Eur Respir J. 2013;41:1257-63.

18. Frye C, Hoelscher B, Cyrys J, Wjst M, Wichmann HE, Heinrich J. Association of lung function with declining ambient air pollution. Environ Health Perspect. 2003;111:383-7.

19. Fuertes E, Bracher J, Flexeder C, Markevych I, Klumper C, Hoffmann B, Kramer U, von Berg A, Bauer CP, Koletzko S, et al. Long-term air pollution exposure and lung function in 15 year-old adolescents living in an urban and rural area in Germany: the GINIplus and LISAplus cohorts. Int J Hyg Environ Health. 2015;218:656-65.

20. Gao Y, Chan EYY, Li LP, He QQ, Wong TW. Chronic effects of ambient air pollution on lung function among Chinese children. Arch Dis Child. 2013;98:128-35.

21. Gehring U, Gruzieva O, Agius RM, Beelen R, Custovic A, Cyrys J, Eeftens M, Flexeder C, Fuertes E, Heinrich J, et al. Air pollution exposure and lung function in children: the ESCAPE project. Environ Health Perspect. 2013;121:1357-64. A well-designed study with harmonized and standardized air pollution data from several European birth cohorts, showing that exposure to air pollution at the current address may result in reduced lung function in school-aged children.

22. Gehring U, Beelen R, Eeftens M, Hoek G, de Hoogh K, de Jongste JC, Keuken M, Koppelman GH, Meliefste K, Oldenwening M, et al. Particulate matter composition and respiratory health the PIAMA birth cohort study. Epidemiology. 2015;26:300-9.

23. Hirsch T, Weiland SK, von Mutius E, Safeca AF, Grafe H, Csaplovics E, Duhme H, Keil U, Leupold W. Inner city air pollution and respiratory health and atopy in children. Eur Respir J. 1999;14:669-77. 
24. Hoek G, Pattenden S, Willers S, Antova T, Fabianova E, BraunFahrlander C, Forastiere F, Gehring U, Luttmann-Gibson H, Grize L, et al. PM10, and children's respiratory symptoms and lung function in the PATY study. Eur Respir J. 2012;40:538-47.

25. Islam T, Urman R, Gauderman WJ, Milam J, Lurmann F, Shankardass K, Avol E, Gilliland F, McConnell R. Parental stress increases the detrimental effect of traffic exposure on children's lung function. Am J Respir Crit Care Med. 2011;184:822-7.

26. Janssen NA, Brunekreef B, van Vliet P, Aarts F, Meliefste K, Harssema $\mathrm{H}$, Fischer $\mathrm{P}$. The relationship between air pollution from heavy traffic and allergic sensitization, bronchial hyperresponsiveness, and respiratory symptoms in Dutch schoolchildren. Environ Health Perspect. 2003;111:1512-8.

27. Lee YL, Wang WH, Lu CW, Lin YH, Hwang BF. Effects of ambient air pollution on pulmonary function among schoolchildren. Int $\mathrm{J}$ Hyg Environ Health. 2011;214:369-75.

28.• Morales E, Garcia-Esteban R, de la Cruz OA, Basterrechea M, Lertxundi A, de Dicastillo MD, Zabaleta C, Sunyer J. Intrauterine and early postnatal exposure to outdoor air pollution and lung function at preschool age. Thorax. 2015;70:64-73. The first study that explored air pollution exposure both in pregnancy and in early life, showing the strongest association for exposure during the 2nd trimester of pregnancy with lung function in $4.5 \mathrm{yr}$ olds.

29. Neophytou AM, White MJ, Oh SS, Thakur N, Galanter JM, Nishimura KK, Pino-Yanes M, Torgerson DG, Gignoux CR, Eng $\mathrm{C}$, et al. Air pollution and lung function in minority youth with asthma in the GALA II (genes-environments and admixture in Latino Americans) and SAGE II (study of African Americans, asthma, genes, and environments) studies. Am J Respir Crit Care Med. 2016;193:1271-80.

30. Nicolai T, Carr D, Weiland SK, Duhme H, von Ehrenstein O, Wagner C, von Mutius E. Urban traffic and pollutant exposure related to respiratory outcomes and atopy in a large sample of children. Eur Respir J. 2003;21:956-63.

31. Nordling E, Berglind N, Melen E, Emenius G, Hallberg J, Nyberg F, Pershagen G, Svartengren M, Wickman M, Bellander T. Trafficrelated air pollution and childhood respiratory symptoms, function and allergies. Epidemiology. 2008;19:401-8.

32.• Oftedal B, Brunekreef B, Nystad W, Madsen C, Walker SE, Nafstad P. Residential outdoor air pollution and lung function in schoolchildren. Epidemiology. 2008;19:129-37. The first study to investigate the association between early life exposure to air pollution and school-age lung function, showing negative association between all time periods of exposure and lung function.

33. Peters JM, Avol E, Gauderman WJ, Linn WS, Navidi W, London SJ, Margolis H, Rappaport E, Vora H, Gong H Jr, et al. A study of twelve Southern California communities with differing levels and types of air pollution. II. Effects on pulmonary function. Am J Respir Crit Care Med. 1999;159:768-75.

34. Raizenne M, Neas LM, Damokosh AI, Dockery DW, Spengler JD, Koutrakis P, Ware JH, Speizer FE. Health effects of acid aerosols on north American children: pulmonary function. Environ Health Perspect. 1996;104:506-14.

35. Rice MB, Rifas-Shiman SL, Litonjua AA, Oken E, Gillman MW, Kloog I, Luttmann-Gibson H, Zanobetti A, Coull BA, Schwartz J, et al. Lifetime exposure to ambient pollution and lung function in children. Am J Respir Crit Care Med. 2016;193:881-8.

36. Schultz ES, Gruzieva O, Bellander T, Bottai M, Hallberg J, Kull I, Svartengren M, Melen E, Pershagen G. Traffic-related air pollution and lung function in children at 8 years of age: a birth cohort study. Am J Respir Crit Care Med. 2012;186:1286-91.

37. Schultz ES, Hallberg J, Gustafsson PM, Bottai M, Bellander T, Bergstrom A, Kull I, Gruzieva O, Thunqvist P, Pershagen G, et al. Early life exposure to traffic-related air pollution and lung function in adolescence assessed with impulse oscillometry. J Allergy Clin Immunol. 2016;138:930-2. The first study to investigate small airway involvement using impulse oscillometry, showing association between increased air pollution levels in infancy and increased resistance in the small airways at 16 years of age.

38. Schwartz J. Lung function and chronic exposure to air pollution: a cross-sectional analysis of NHANES II. Environ Res. 1989;50: 309-21.

39. Sugiri D, Ranft U, Schikowski T, Kramer U. The influence of largescale airborne particle decline and traffic-related exposure on children's lung function. Environ Health Perspect. 2006;114:282-8.

40. Svendsen ER, Gonzales M, Mukerjee S, Smith L, Ross M, Walsh D, Rhoney S, Andrews G, Ozkaynak H, Neas LM. GIS-modeled indicators of traffic-related air pollutants and adverse pulmonary health among children in El Paso, Texas. Am J Epidemiol. 2012;176:S131-41.

41. Wang M, Gehring U, Hoek G, Keuken M, Jonkers S, Beelen R, Eeftens M, Postma DS, Brunekreef B. Air pollution and lung function in Dutch children: a comparison of exposure estimates and associations based on land use regression and dispersion exposure modeling approaches. Environ Health Perspect. 2015;123:847-51.

42. Wjst M, Reitmeir P, Dold S, Wulff A, Nicolai T, von LoeffelholzColberg EF, von Mutius E. Road traffic and adverse effects on respiratory health in children. BMJ. 1993;307:596-600.

43. Avol EL, Gauderman WJ, Tan SM, London SJ, Peters JM. Respiratory effects of relocating to areas of differing air pollution levels. Am J Respir Crit Care Med. 2001;164:2067-72.

44. Gauderman WJ, McConnell R, Gilliland F, London S, Thomas D, Avol E, Vora H, Berhane K, Rappaport EB, Lurmann F, et al. Association between air pollution and lung function growth in southern California children. Am J Respir Crit Care Med. 2000;162:1383-90.

45. Gauderman WJ, Gilliland GF, Vora H, Avol E, Stram D, McConnell R, Thomas D, Lurmann F, Margolis HG, Rappaport EB, et al. Association between air pollution and lung function growth in southern California children: results from a second cohort. Am J Respir Crit Care Med. 2002;166:76-84.

46.• Gauderman WJ, Avol E, Gilliland F, Vora H, Thomas D, Berhane K, McConnell R, Kuenzli N, Lurmann F, Rappaport E, et al. The effect of air pollution on lung development from 10 to 18 years of age. N Engl J Med. 2004;351:1057-67. The first longitudinal study to follow children over a 8-year period up to young adulthood. The authors could demonstrate associations between current levels of air pollution and attenuated lung function growth.

47. Gauderman WJ, Vora H, McConnell R, Berhane K, Gilliland F, Thomas D, Lurmann F, Avol E, Kunzli N, Jerrett M, et al. Effect of exposure to traffic on lung development from 10 to 18 years of age: a cohort study. Lancet. 2007;369:571-7.

48.• Gauderman WJ, Urman R, Avol E, Berhane K, McConnell R, Rappaport E, Chang R, Lurmann F, Gilliland F. Association of improved air quality with lung development in children. N Engl $\mathrm{J}$ Med. 2015;372:905-13. A a very important longitudinal study, following three cohorts consecutively over a 13-year-period, showing that improvements in air quality were associated with positive effects on 4-year lung function growth.

49. He QQ, Wong TW, Du L, Jiang ZQ, Gao Y, Qiu H, Liu WJ, Wu JG, Wong A, Yu TS. Effects of ambient air pollution on lung function growth in Chinese schoolchildren. Respir Med. 2010;104:1512-20.

50. Horak F, Studnicka M, Gartner C, Spengler JD, Tauber E, Urbanek R, Veiter A, Frischer T. Particulate matter and lung function growth in children: a 3-yr follow-up study in Austrian schoolchildren. Eur Respir J. 2002;19:838-45.

51. Molter A, Agius RM, de Vocht F, Lindley S, Gerrard W, Lowe L, Belgrave D, Custovic A, Simpson A. Long-term exposure to PM10 and NO2 in association with lung volume and airway resistance in the MAAS birth cohort. Environ Health Perspect. 2013;121:12328. A well-designed longitudinal study, improving the individual 
air pollution exposure assessment by including a micro-environmental model. One of few studies to include bronchodilator response. The study found deficits in lung function growth in relation to early life exposure. Stronger effects after bronchodilator treatment.

52. Neuberger M, Moshammer H, Kundi M. Declining ambient air pollution and lung function improvement in Austrian children. Atmos Environ. 2002;36:1733-6.

53. Rojas-Martinez R, Perez-Padilla R, Olaiz-Fernandez G, MendozaAlvarado L, Moreno-Macias H, Fortoul T, McDonnell W, Loomis $\mathrm{D}$, Romieu I. Lung function growth in children with long-term exposure to air pollutants in Mexico City. Am J Respir Crit Care Med. 2007;176:377-84.

54.• Schultz ES, Hallberg J, Bellander T, Bergstrom A, Bottai M, Chiesa F, Gustafsson PM, Gruzieva O, Thunqvist P, Pershagen G, et al. Early-life exposure to traffic-related air pollution and lung function in adolescence. Am J Respir Crit Care Med. 2016;193:171-7. The first study to follow children with life-time air pollution exposure data up to adolescence. Using advanced life-course statistical approaches, negative association between infancy exposure and lung function at 8 and 16 years of age were shown.

55. Perez L, Rapp R, Kunzli N. The year of the lung: outdoor air pollution and lung health. Swiss Med Wkly. 2010;140:w13129.

56. Brunekreef B, Holgate ST. Air pollution and health. Lancet. 2002;360:1233-42.

57. Romieu I, Garcia-Esteban R, Sunyer J, Rios C, Alcaraz-Zubeldia M, Velasco SR, Holguin F. The effect of supplementation with omega-3 polyunsaturated fatty acids on markers of oxidative stress in elderly exposed to PM(2.5). Environ Health Perspect. 2008;116: $1237-42$.

58. Gruzieva $\mathrm{O}, \mathrm{Xu} \mathrm{CJ}$, Breton CV, Annesi-Maesano I, Anto JM, Auffray C, Ballereau S, Bellander T, Bousquet J, Bustamante M, et al. Epigenome-wide meta-analysis of methylation in children related to prenatal NO2 air pollution exposure. Environ Health Perspect. 2017;125:104-10.

59. Gref A, Merid SK, Gruzieva O, Ballereau S, Becker A, Bellander T, et al. Genome-wide interaction analysis of air pollution exposure and childhood asthma with functional follow-up. 2017;195:1373-83.

60. Churg A, Brauer M, del Carmen A-CM, Fortoul TI, Wright JL. Chronic exposure to high levels of particulate air pollution and small airway remodeling. Environ Health Perspect. 2003;111: 714-8.

61. Annesi-Maesano I, Dinh-Xuan AT. Is exhaled nitric oxide a marker of air pollution effect? Eur Respir J. 2016;47:1304-6.

62. Turnovska TH, Marinov BI. The influence of air pollution during intrauterine development and early childhood on respiratory functions at later age. Int J Hyg Environ Health. 2009;212:519-32.

63. Moshammer H, Hoek G, Luttmann-Gibson H, Neuberger MA, Antova T, Gehring U, Hruba F, Pattenden S, Rudnai P, Slachtova $\mathrm{H}$, et al. Parental smoking and lung function in children: an international study. Am J Respir Crit Care Med. 2006;173:1255-63.

64. van der Wiel E, ten Hacken NH, Postma DS, van den Berge M. Small-airways dysfunction associates with respiratory symptoms and clinical features of asthma: a systematic review. J Allergy Clin Immunol. 2013;131:646-57.

65. Lipworth B, Manoharan A, Anderson W. Unlocking the quiet zone: the small airway asthma phenotype. Lancet Respir Med. 2014;2: 497-506. An excellent review on small airway function and respiratory disease.

66. Shi Y, Aledia AS, Tatavoosian AV, Vijayalakshmi S, Galant SP, George SC. Relating small airways to asthma control by using impulse oscillometry in children. J Allergy Clin Immunol. 2012;129:671-8
67. McNulty W, Usmani OS. Techniques of assessing small airways dysfunction. Eur Clin Respir J. 2014;1

68. Quanjer PH, Weiner DJ, Pretto JJ, Brazzale DJ, Boros PW. Measurement of FEF25-75\% and FEF75\% does not contribute to clinical decision making. Eur Respir J. 2014;43:1051-8.

69. Kuehl PJ, Anderson TL, Candelaria G, Gershman B, Harlin K, Hesterman JY, Holmes T, Hoppin J, Lackas C, Norenberg JP, et al. Regional particle size dependent deposition of inhaled aerosols in rats and mice. Inhal Toxicol. 2012;24:27-35.

70. Berend N. Contribution of air pollution to COPD and small airway dysfunction. Respirology. 2016;21:237-44.

71. Pellegrino R, Viegi G, Brusasco V, Crapo RO, Burgos F, Casaburi R, Coates A, van der Grinten CP, Gustafsson P, Hankinson J, et al. Interpretative strategies for lung function tests. Eur Respir J. 2005;26:948-68.

72. Goldman MD, Saadeh C, Ross D. Clinical applications of forced oscillation to assess peripheral airway function. Respir Physiol Neurobiol. 2005;148:179-94.

73. Foy BH, Kay D. A computational comparison of the multiple-breath washout and forced oscillation technique as markers of bronchoconstriction. Respir Physiol Neurobiol. 2017;240:61-9.

74. Moshammer H, Hutter HP, Hauck H, Neuberger M. Low levels of air pollution induce changes of lung function in a panel of schoolchildren. Eur Respir J. 2006;27:1138-43.

75. Oppenheimer BW, Goldring RM, Herberg ME, Hofer IS, Reyfman PA, Liautaud S, Rom WN, Reibman J, Berger KI. Distal airway function in symptomatic subjects with normal spirometry following World Trade Center dust exposure. Chest. 2007;132:1275-82.

76. Carey MA, Card JW, Voltz JW, Arbes SJ Jr, Germolec DR, Korach KS, Zeldin DC. It's all about sex: gender, lung development and lung disease. Trends Endocrinol Metab. 2007;18:308-13.

77. Doershuk CF, Fisher BJ, Matthews LW. Specific airway resistance from the perinatal period into adulthood. Alterations in childhood pulmonary disease. Am Rev Respir Dis. 1974;109:452-7.

78. Hsu HH, Chiu YH, Coull BA, Kloog I, Schwartz J, Lee A, Wright RO, Wright RJ. Prenatal particulate air pollution and asthma onset in urban children. Identifying sensitive windows and sex differences. Am J Respir Crit Care Med. 2015;192:1052-9.

79. Keselman A, Heller N. Estrogen signaling modulates allergic inflammation and contributes to sex differences in asthma. Front Immunol. 2015;6:568.

80. Carlsten C, Brauer M, Dimich-Ward H, Dybuncio A, Becker AB, Chan-Yeung M. Combined exposure to dog and indoor pollution: incident asthma in a high-risk birth cohort. Eur Respir J. 2011;37: 324-30

81. Jorres R, Nowak D, Magnussen $H$. The effect of ozone exposure on allergen responsiveness in subjects with asthma or rhinitis. Am J Respir Crit Care Med. 1996;153:56-64.

82. Carlsten C, Blomberg A, Pui M, Sandstrom T, Wong SW, Alexis N, Hirota J. Diesel exhaust augments allergen-induced lower airway inflammation in allergic individuals: a controlled human exposure study. Thorax. 2016;71:35-44. In this controlled experimnetal study, the authors conclude that allergic individuals are a susceptible population to the deleterious airway effects of diesel exhaust.

83. Holgate ST. The sentinel role of the airway epithelium in asthma pathogenesis. Immunol Rev. 2011;242:205-19.

84. Clifford RL, Jones MJ, MacIsaac JL, McEwen LM, Goodman SJ, Mostafavi S, Kobor MS, Carlsten C. Inhalation of diesel exhaust and allergen alters human bronchial epithelium DNA methylation. J Allergy Clin Immunol. 2016; 